\title{
NEW CONTROL METHODS IN STIMULATING DRIVE FOR POWER GENERATION IN MARINE APPLICATION
}

\author{
VEERAKUMAR
}

Assistant Professor, Department of Electrical and Electronic Engineering (Marine), AMET University,

Chennai, Tamilnadu, India

\begin{abstract}
In recent years the electric drive system is used in various applications because the power is the most important for all. The proposed paper electric drive based power production using the pulse width modulation for marine application. In general, the motor has high switching frequency $(f s)$ the current ripple is low. In any case, in high power marine applications, where impulsion engines are in the multi-megawatt extend, bring down inverter exchanging recurrence is favoured for diminishing exchanging misfortunes. Synchronous ideal heartbeat width regulation (SOP) is a mounting low transferring recurrence system which empowers the decrease of exchanging recurrence without bargaining all out current consonant contortion (THDi).

KEYWORDS: Multilevel Inverter, Synchronous Optimal Pulse Width Modulation, Thermal Losses
\end{abstract}

Received: Oct 06, 2017; Accepted: Oct 26, 2017; Published: Jan 30, 2018; Paper Id.: IJMPERDFEB201899

\section{INTRODUCTION}

Enthusiasm for marine jolt was revived in the 1980s with the development obtained in the field of energy hardware. The development of variable speed drives (VSDs) killed the reliance of a marine vessel's electric impetus transport recurrence on its cruising speed. With this discouraging component removed, electric propulsion frameworks have, from that point forward, been progressively supplanting mechanical drive frameworks. The substitution of mechanical couplings between the prime mover and the propeller with an electrical system gives a few advantages - more prominent adaptability in ship format configuration, expanded consistent quality, lessened support cost, upgraded dynamic execution and decreased fuel utilisation (F. Boattini, et al., 1998), (Wenjie Chen, et al., 2010) and (D. G. Wilson, et al., 2016).

$690 \mathrm{~V} / 60 \mathrm{~Hz}$ low voltage AC (LVAC), has appeared in Figure 1, has been the most famous if not the default framework for marine impetus drive applications because of its development, consistent quality and accessibility of low voltage exchanging gadgets (IGBTs/IGCTs). Customary two-level (2L) inverters or threelevel (3L) inverters (Kannan, G et al., 2015) Reactive power optimisation using firefly algorithm are utilised to change over the DC yield of the front-end rectifier into a variable-voltage-variable-recurrence source to control the speed of the impetus engine. For any regulation procedure employed to control the inverter, the primary standard stays same - semiconductor switches affecting impermanent associations at high reiteration rates between two dc terminals and the three periods of the air conditioner engine.

Typically the trade-off made between these two opposing goals manages how low the exchanging recurrence can be brought down to while utilising a specific balance system. Among the new space vector beat 
width modulation (SVPWM) is the most perceived and embraced plot for (Priya, T.S., et al., 2014) Isolation of Marine organisms and their antifungal studies, In Computational Intelligence in Data Mining forcing low symphonious substance on machine windings. The main impediment, however, is again with the exchanging recurrence which must be kept over 1 $\mathrm{kHz}$ to keep up the middle of the road contortion of the machine's stator current waveforms (C. L. Su., et al., 2016), (K. Rathore, et al., 2010) and (L. Saad, et al., 2016). The synchronous based ac load connected system is shown in figure 1.

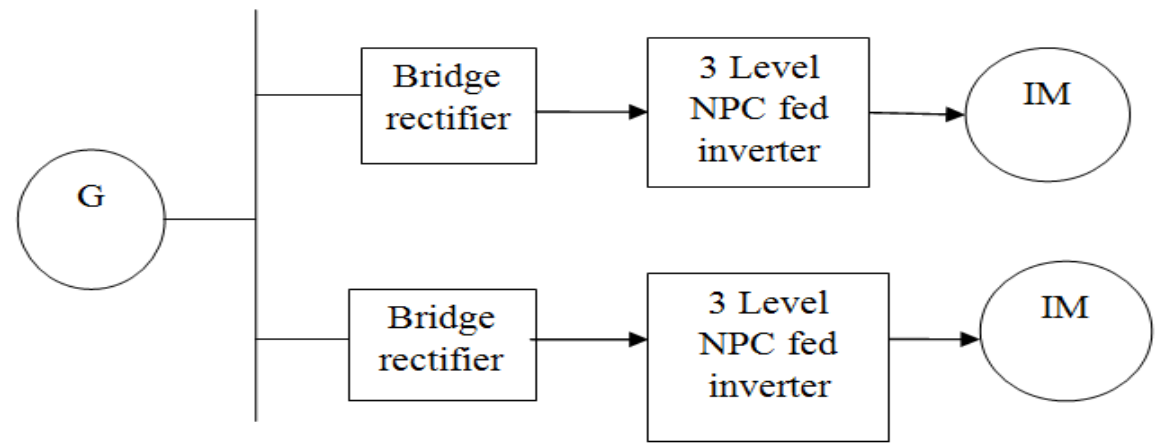

Figure 1: Synchronous Generator Based AC Load Bus Connected System

\section{SIMULTANEOUS PULSE WIDTH MODULATION}

In a (Kumar, P.S., et al., 2015) Pull-in voltage study of various structured cantilever and fixed-fixed beam models using COMSOL multiphysics the $3 \mathrm{~L}$ inverter five phases (Figure 2), for a given dc interface voltage Vdc, the most significant yield potential $\left(\mathrm{V}_{\mathrm{AO}}, \mathrm{V}_{\mathrm{BO}}, \mathrm{V}_{\mathrm{CO}}\right)$ can be created by working the inverter in ten stage mode. This includes keeping the central two switches of each stage on for $180^{\circ}$ and the last two switches on for the following $180^{\circ}$ of the primary cycle as appeared in Figure 3(a). The sufficiency of the inserted central sinusoid $V_{A O}$, 1in the $V_{A O} P W M$ waveform is given by (1). By presenting a few scores or exchanging edges inside the waveform as appeared in Figure 3(b) while keeping up halfwave symmetry and quarter-wave symmetry, the sufficiency of VAO, one gets altered to (2a) as indicated by Fourier Analysis.

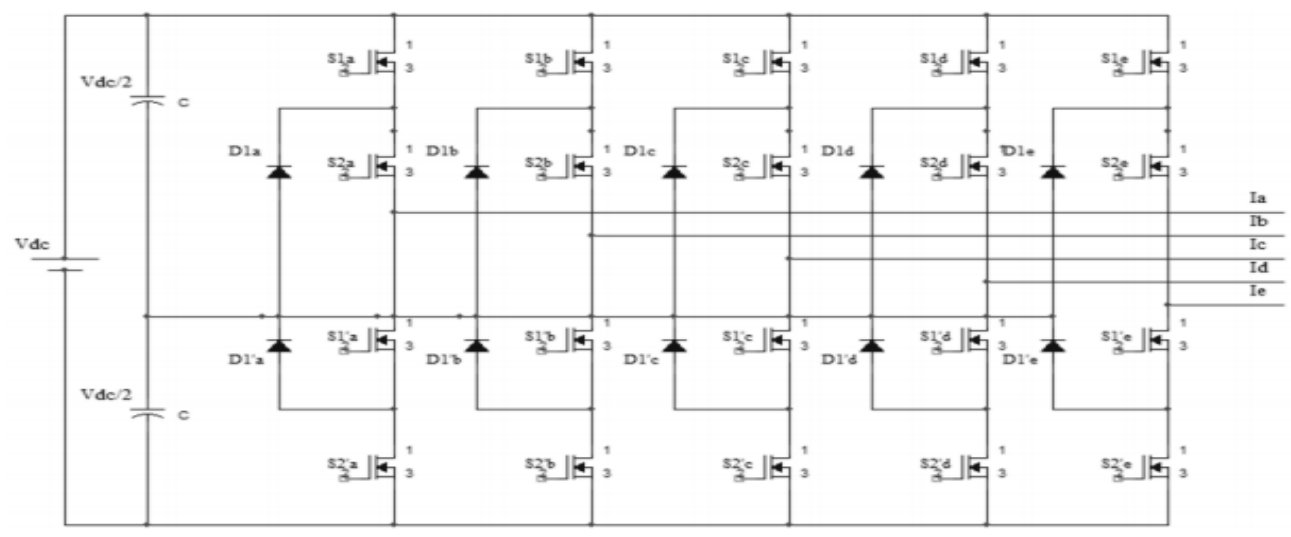

Figure 23 Level Five Phase NPC Fed Inverter

\section{IMPLEMENTATION OF PROPOSED OPTIMAL PULSE WIDTH MODULATION}

The implemented switching frequency (Alf Kare Adnanes) Studies on Hall Effect and DC conductivity measurements of semiconductor thin films prepared by chemical bath deposition (CBD) method. These paper constraints 
the Storage System Characteristics and comparisons (H. Ibrahim et al). The performance of the $3 \mathrm{MW}$ main propeller when it is running at full load/rated speed while fed from a $3 \mathrm{~L}$ inverter is simulated. Production of the inverter with the supercapacitor for vector controlled induction motor drives is said in (Yamashita et al 2006). The NPC based three level is shown in figure 4. The three-level line to line voltages is shown in figure 5.The comparison curve of proposed synchronous optimal PWM and conventional SVPWM is shown in figure 6. This paper determines the Easy and Efficient Tuning of PI Controllers for Electrical Drives (Tiemele ANE and Luc LORON 2006) and (Mohamed-Yacine Ayad and Serge Pierfederici, 2007). (T. Hemalatha 2012) discussed the method that distributes the computation workload from the DMV to RSBs while releasing only a limited amount of information by using hash collisions.

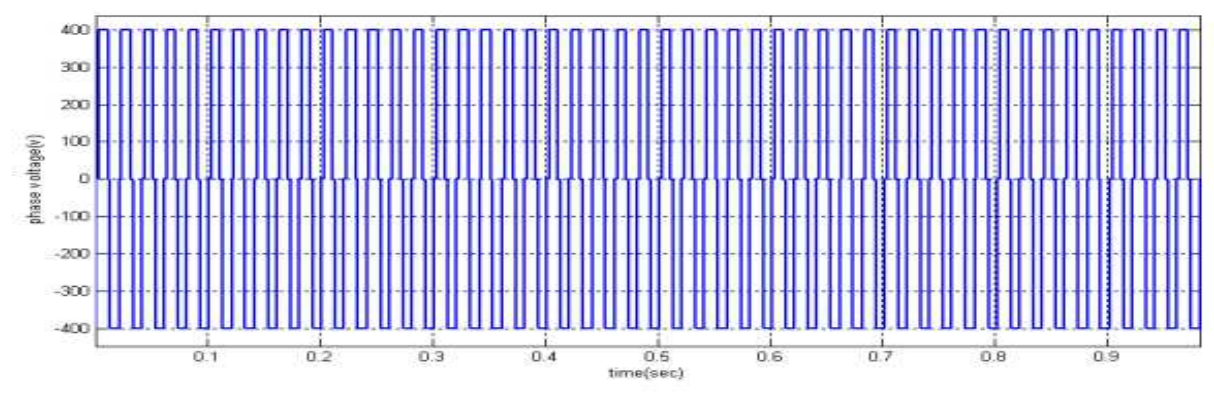

Figure 4: Three Level Five Phase NPC Based Inverter Voltage

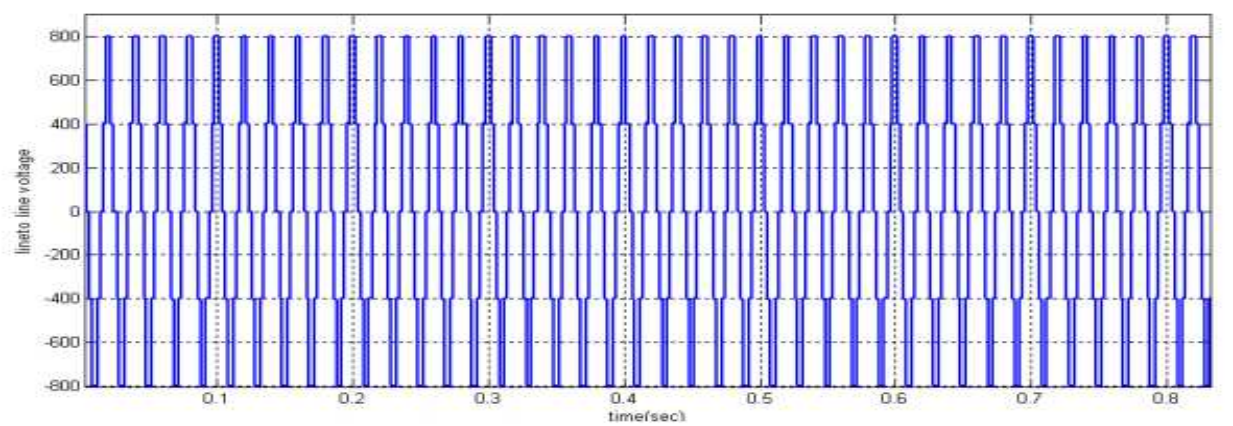

Figure 5: NPC Three Level Line to Line Voltages

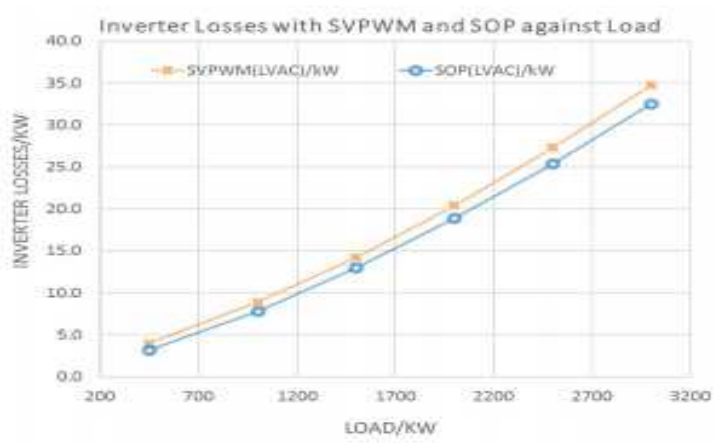

Figure 6: Comparison between SVPWM and SOPWM Inverter Losses

\section{CONCLUSIONS}

For high power marine drive engines, low inverter exchanging recurrence is wanted to breaking point transferring misfortunes. Modelisation er characterisation des supercondensateurs a couch double electric utilises en Electronique de puissance is described (Farid Belhachemi). At a similar time, low engine current THD is coveted, to decrease copper 
misfortunes and limit torque throbs. In this paper, synchronous ideal pulse width balance is explored sometime recently being actualised for a $3 \mathrm{~L}$ inverter.

\section{REFERENCES}

1. F. Boattini, R. Galli, A. Monti and G. Secondo, "Integrated design methodology for electrical drives: a marine application experience," Industrial Electronics Society, 1998. IECON '98. Proceedings of the 24th Annual Conference of the IEEE, Aachen, 1998, pp. 591-595 vol.2.

2. Wenjie Chen, A. K. Ådnanses, J. F. Hansen, J. O. Lindtjørn and Tianhao Tang, "Super-capacitors based hybrid converter in the marine electric propulsion system," The XIX International Conference on Electrical Machines - ICEM 2010, Rome, 2010, pp. 1-6.

3. D. G. Wilson, R. D. Robinett, W. W. Weaver, R. H. Byrne and J. Young, "Nonlinear Power Flow Control design of high penetration renewable sources for AC inverter based microgrids," 2016 International Symposium on Power Electronics, Electrical Drives, Automation and Motion (SPEEDAM), Anacapri, 2016, pp. 701-708.

4. Kannan, G., Subramanian, D.P. and Shankar, R.U., 2015. Reactive power optimisation using firefly algorithm. In Power Electronics and Renewable Energy Systems (pp. 83-90). Springer India.

5. Priya, T.S., Balasubramanian.V, 2014. Isolation of Marine organisms and their antifungal studies, Biosciences Biotechnology Research Asia, 11(special edition), pp. 343-347.

6. C. L. Su, Chi-Hsiang Liao, Tso-Chu Chou, Min-Hung Chou and J. M. Guerrero, "Variable flow controls of closed system pumps for energy savings in maritime power systems," 2016 IEEE Industry Applications Society Annual Meeting, Portland, OR, 2016, pp. 1-8.

7. K. Rathore, J. Holtz and T. Boller, "Synchronous Optimal Pulse width Modulation for Low-Switching-Frequency Control of Medium-Voltage Multilevel Inverters," in IEEE Transactions on Industrial Electronics, vol. 57, no. 7, pp. 2374- 2381, July 2010.

8. L. Saad, H. Hicham and F. Khalid, "Optimal tracking, modelling and control of aerogenerator based on PMSG driven by a wind turbine," 2016 IEEE International Conference on Renewable Energy Research and Applications (ICRERA), Birmingham, 2016, pp. 891-896.

9. G.Sravanthi, Vanam Srujana Devi, Koganti Sri Lakshmi\& N.Uday Kumar, Simulation of Grid Connected Modified 9 Level Cascaded H-Bridge Multilevel Inverter with Reduced Switches for Solar Power Application, International Journal of Electrical and Electronics Engineering Research (IJEEER), Volume 3, Issue 5, September - October 2015, pp. 59-70

10. Kumar, P.S., Elavarasi, R., Eladi, P.B. and Gopikrishnan, M., 2015. Pull-in voltage study of multiple structured cantilevers and fixed-fixed beam models using COMSOL Multiphysics. Indian Journal of Science and Technology, 8(14).

11. Alf Kare Adnanes "Reduction of fuel consumption and environmental footprint for AHTS and OSVS using electric or hybrid propulsion" ABB AS, Business Unit Marine, P.O. Box 94, NO-1375 Billingstad, Norway

12. H. Ibrahim, A. Ilinca and J. Perron, Energy "Storage SystemCharacteristics and comparisons, Wind Energy Research Laboratory (WERL)" Université du Québec à Rimouski Papers from Conference Proceedings.

13. Yamashita, K., Tomida, T. and Matsuse, K. "Performance of the inverter with the supercapacitor for vector controlled induction motor drives", IEEE Industrial Electronics" IECON 2006 - 32nd Annual Conference, 6-10 Nov. 2006, Pages 946 951, 10.1109/IECON.2006.347928

14. Tiemele ANE, Luc LORON "Easy and Efficient Tuning of PI Controllers for Electrical Drives" IECON'06, 
ParisDissertations.

15. Mohamed-Yacine Ayad and Serge Pierfederici "Voltage regulatedhybrid DC power source using supercapacitors as energy storage device” Ph.D. dissertation, l'Institut National Polytechnique de Lorraine, 2007

16. Farid Belhachemi "Modelisation er caracterisation des supercondensateurs a couche double electrique utilises en electronique de puissance" Ph.D.

17. T. Hemalatha, Detecting Sybil Attack with a Scalable Protocol, International Journal of MC Square Scientific Research (IJMSR), Vol 4, No 1, 2012, pp. 35-41. 
